\title{
Beta-1B Glycoprotein Measurement
}

National Cancer Institute

\section{Source}

National Cancer Institute. Beta-1B Glycoprotein Measurement. NCI Thesaurus. Code C127607.

The determination of the amount of beta-1B glycoprotein present in a sample. 